\title{
The Prospective Economic and Social Benefits of E- Learning with Special Focusing on the Sudanese Experience
}

\author{
Fatima Rayan Awad \\ Information Systems Department, College of \\ Computer Engineering \& Science, Salman Bin \\ Abdulaziz University.Riyadh, Saudi Arabia
}

\author{
Samani A.Talab \\ Computer Science, Neelain University. Khartoum, \\ Sudan
}

\begin{abstract}
The aim of this paper is to analyze the educational, economical and benefits of E-learning. This study reflected that the e-learning has greater beneficial role in human and social abilities beside its important role in replenishing the universal shortage in math and science teachers and in solving the problem on of laboratories shortage in poor countries. The paper has also indicated the rapid growth of e-learning economics which is expected to reach 100 billion dollars in 2015. Lastly, the paper described the Sudanese condition as an example of poor African countries.
\end{abstract}

\section{Keywords}

Internet - education- e-learning- technology- economicalhuman- social- analysis- benefits- learner- e-learning market.

\section{INTRODUCTION}

Internet is one of the greatest human technologies of all times, particularly in field of learning and knowledge exchange. Elearning is similar to E-Health, E-Commerce, E-Government and all other applications starting with the letter E, which use internet technology to provide the intended application or service [1]. It may be a source of confusion for a lot of people, that they cannot differentiate between using of computer and using of intent for implementation of an electronic service. for instance, Gin [2] mentioned that, many people mistakenly believe that e-learning means using of computer as educational instrument. As a matter of fact, e-learning means using of internet as a route of communication and interaction medium between the teacher and students, similarly to the physical presence of a teacher with students in the classroom. Interaction between students themselves in e-learning is also possible through multi-channels, which facilitate response and flexibility among students to satisfy their needs [3], [4].

E-leaning is a natural and logical outcome of new generations' needs. With the technological development of today in mind, there are three essential factors to be considered in educational systems, namely: means of communication, quality and cost.
Technology can enhance tools of getting access to learning and quality improving, as well as providing cost effective education [5].

\section{THE LIFE-CYCLE OF THE E- LEARNING PROCESS}

The life-cycle of the e-learning process from the planning and preparation of a course to the consumption by the learners is depicted in Figure 1. The life cycle, as presented in Figure 1, comprises of four phases, namely: the design phase, where the targets and requirements are specified, the production phase, where content is produced, assembled and packaged for distribution, the deployment phase, which requires the collaboration of learners in order to distribute the appropriate content per case, and the assessment phase, where the outcome of the whole process is evaluated. For the successful design of a learning process one should first define the required features of learners' profile and the recommended competencies. It should also specify in detail the educational targets to be achieved by the end of the learning process. The production phase integrates the production of content modules, their build up based on the initial design, and the packaging of the content to be delivered. The deployment phase that follows should consider the ability of users to access the content and collaborate during the learning process. The learning process ends up with the assessment of learners through tests and other activities and of the process itself through evaluation forms. At the end of every phase useful information is collected and fed back to every previous phase of the process. This facilitates the improvement of the whole process and leads to better solutions for learners and educators. As an example, the information gathered during the deployment phase, which concerns actual learners' needs and level of satisfaction is used as an input in the production phase, in order to reassemble learning objects and produce more competitive packaged solutions. [24] of electronic leaning, either for purposes of promoting school achievements or for direct curriculum presentation. 




Fig1: The life cycle of e-learning process [24]

\section{PREVIOUS STUDIES}

A survey was conducted through internet, for university students in UK, Romania, Finland and Hungary, who were receiving their education either through traditional systems or internet. The survey was aiming to detect the requirements of digitally-minded students, which enable them to master their digital domains [4]. Other fellow students referred to those digitally-minded, as digital students. Analysis of the survey revealed that how the optimum learning environment for those students was structured and used. It was an environment composed of a number of elements including internet and interactivity technologies. This is to consolidate communication between the teacher and the student and among the students themselves, through using of multiple media channels, giving customizability and flexibility which suit students' needs [4]. Further, a number of studies were carried out in US, to mention here just as an example, the study which took place in Texas state's public schools. The study indicated that almost all of school headmasters confirmed the benefits of internet based teaching methods i. e. e-learning. Moreover, using of internet in education making assessment and follow-up of teachers' capabilities easier [6], [7], [8], [9]. Electronic schools are now a reality of regular education in US and existing in all states and services of elearning is provided in more than $75 \%$ of schools. Headmasters in more than $80 \%$ of schools reported that they had students who were completely dependent on internet to have their education. That was in addition to $38 \%$ of students who at least studied one of their curriculum through internet. As for using of internet to increase accomplishments of students in school, more than $80 \%$ of school headmasters in the same study, assured the benefits which their students achieved. In the same study, more than $87 \%$ of students in age range of $12-17$, said that they were using internet [10]. Since late years of nineties of last centuries, after comprehensive educational studies, schools in US were connected with internet, after extensive educational studies, to make available of electronic leaning, either for purposes of promoting school achievements or for direct curriculum presentation.

In New Zealand, a trial was conducted in schools preceded designing and implementation of e-learning in country, and was introduced mainly to train teachers [11]. In Malaysia, nearly all schools are already connected with internet to provide e-learning services, and such schools are referred to as intelligent schools [9]. In South Korea all schools are connected with internet service since 2005 [12], [13].

Finally, importance of e-learning was already well-established in the developed nations in North America, Europe, Australia and New Zealand as well as in technologically inspired nations of South Asia, where schools are connected to internet services and provided with computers.

\section{ANALYSIS OF E-LEARNING EDUCATIONAL BENEFITS}

It is not intended here to discuss the benefits of e-learning regarding the flexibility and simplicity it may provide to update curricula, easy communication between teacher and students and continuous students' assessment in order to promote their accomplishments. Rather, the discussion will address the usefulness of e-learning in solving an educational problem which is not only facing poor nations, but also developed ones such as US. It is the problem of shortage of math and science teachers. Some of the educational statistics in US, stated that $50 \%$ of math teachers and $40 \%$ of science teachers in intermediate schools, were either partially or completely under qualified to deliver those subjects in schools. In high schools the situation was little bit better, and the ratio was $15 \%$ and $11 \%$, respectively. The study added that, e-learning may help in training of under qualified math and science teachers [2], [14]. The same problem is existing in a lot of countries in Europe, South Asia and Middle East. Oil producing countries such as Saudi Arabia and other Gulf states, trying to overcome the problem by hiring math and science teachers from other low income Arab countries such as Egypt, Sudan and Morocco. In case of Sudan this condition results in a severe shortage of math and science teachers, particularly in rural schools. The profound deficiency of math and science teachers in rural areas, leads to a situation where $70 \%$ of students who sit there for Sudanese Secondary School Examination, are of arts branch (nonscientific course) due to lack of teaching these subjects in their schools. Good qualified math and science teachers usually prefer to work in big cities where they are employed in well-paid jobs by non-governmental schools. They are also making good fortunes out of giving lessons privately to students. Another fact is that, the poor infrastructure is hardly attractive for anyone to live in rural areas [15]. Hence, there is a similarity in situation of Sudan and US regarding shortage of qualified math and science teachers, though in US people prefer life in rural areas than in big cities. Besides, another problem of rural schools in Sudan is the lack of laboratories. Therefore, implementation of e-learning system to qualify teachers as in US, may solve the problem of shortage. But it is more important that e-learning should be used in direct teaching of some subjects in schools, as it is now practiced in teaching of some specialties in some state universities in Sudan. At present, Informatics Development Fund is carrying 
out job of equipping schools with communication infrastructure, computer sets and applications. Teachers are also trained, under special training program under the Open University, to qualify them for e-learning in schools [16].

This is at the level of public education. Regarding high education, the Fund has established the Sudanese universities network, which gives access to international electronic libraries and world universities which provide free curriculum teaching. It is needless to say that, such steps are of great support for the educational process and to overcome lecturers' shortage in Sudanese universities in general and state universities in particular [16]

\section{ANALYSIS OF SOCIAL AND HUMAN BENEFITS}

Since mid of the first decade of this century, and to be more precisely, after the informatics summit in Tunisia, there is a new world humane trend for making knowledge free for all through internet. The renowned Massachusetts Institute of Technology (MIT), was the first high education institution, to make all of its curricula electronically available for free through internet (electronic curriculum). Then, followed by many universities such as University of New York and others. Now, almost all of universities - in developed nations - make their educational programs available through internet. This will help poor universities in third world to make use of these curricula and to solve the problem of faculty and lab deficiencies. On the other hand, besides overcoming of geographical and cultural barriers, e-learning facilitates interaction and acquaintance between people, and the experience of Baccalaureate International is a good example. This is a civil organization seated in Geneva, Switzerland, which has an e-learning program for school students, connecting about 1500 schools in 115 countries. In the experience students in a German classroom were connected with their counterparts in a Canadian classroom, to exchange articles about the history of Second World War. Canada, as a nation under the sovereignty of British Crown, was fighting beside Britain against Nazi Germany. Monique Kin, organizer of the program, stated that interaction and acquaintance between students was a very positive experience [Adacosman Report][17].

The African Virtual University of Nairobi in Kenya, has a good experience of making use of educational programs of famous universities in the world, to provide e-learning to students from poor African countries [18]. There are also a lot of experiences of charity organizations who are actively donating for training of professionals and teachers in particular.

A study in US [2], stated that about $50 \%$ of Afro-Americans and Hispanics were studying in high schools, only $20 \%$ out of them would complete their education, while normally $50 \%$ of students in cities complete their school. This is consistent with the percentages shown above because majority of the rural populations are of the white ethnic group of high economical standards. Accordingly, poor students of African and Hispanic origins cannot complete their secondary school, regardless of the reasons for severing their education [18].

E-learning gives chance of education for poor students who do not afford to pay for university tuition fees, those who interrupt their education to start work in early ages, or those who are living in remote areas where closed systems of education not available. It is mentioned earlier here that, elearning is overcoming barriers of age, ethnic origin, geography and educational differences. The student can make the appropriate selection to study electronically, from the level of elementary school up to university or professional education.

In conclusion, e-learning is a human trend to make knowledge available for all, regardless of social, ethnic, age and geographical differences. E-learning deals with human-being as a human-being, and helps poor to have their chance in acquiring knowledge.

\section{ANALYSIS OF E-LEARNING ECONOMICAL BENEFITS}

It is not intended here to consider the economical benefits of e-learning with regard to reduction in cost of the educational process. This which include cost of construction of classrooms, schools or universities as well as wages of teachers, employees and workers [19], in addition to other indirect benefits such as promotion of achievements and obtaining of knowledge. Rather, the discussion will focus on the economical benefits of e-learning from business and marketing point of view. People now are talking about knowledge economics, which means business related to marketing of knowledge using modern culture of communications, information and applications. Taking this concept into consideration, e-learning, definitely, represents the best example of knowledge economics. There is a huge demand for learning through internet, and there is a competition at technical, educational and scientific levels between companies to satisfy this demand. As a result new markets emerging and more will come up [20]. Informatics market does not need a special industrial infrastructure, but it requires the necessary communication network, beside development in level of education and related investments.

Some countries became aware of this requirements at early stage, and accordingly they established special technological colleges for enrollment of outstanding informatics students from secondary schools. Many countries such as Malaysia, India, Singapore and South Korea in addition to Quebec province in Canada and Victoria state in Australia, attracting foreign investments due to the availability of qualified informatics manpower. Even, some international companies prefer to employ highly skillful people in these countries over their own citizens, and for the reasons of reducing operation costs. Moreover, economies of hosting countries will be greatly benefited by such investments. Benefits to above mentioned countries not only limited to attraction of foreign investments, but also extended to exporting of informatics products such as softwares, applications and electronic solutions. Some countries, only few years ago were considered developing countries, now they are among leading countries in exporting technology, and their income from such business not less than that of industrial income. It is not possible for these countries to realize such achievements without having proper development of their human resources, education, informatics and communication infrastructures and establishment of technological colleges in addition to introduction of technology to high education. Within the following decade the number of students who will be graduated from secondary schools and universities in Sudan, will reach millions. Those students shall be qualified to be a source of national income, through appropriate technical training, to be productive elements in the national economy. 


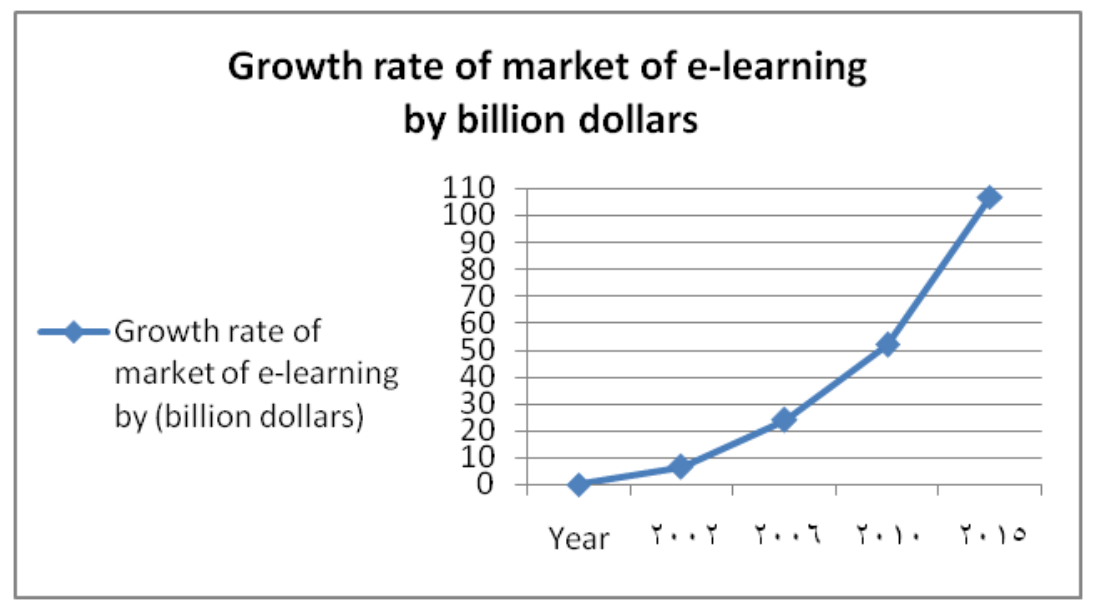

\section{Fig2: Growth rate of market of e-learning}

The distinguished feature of informatics technology is that, people can work and participate in production from anywhere, regardless of their geographical existence, as it is required for jobs in trade, agriculture or industry. Moreover, age is not an essential factor in informatics production; many profitable companies in this field depend on young workers who are their twenties. Sony, for instance, $95 \%$ of its electronic games programmers are under twenty of their age.

Code fob and Alpha Metric, UK-based Consultancy, in collaboration with the concerned authorities in UK, conducted a statistical survey through internet, between January and April 2001, for detection of the range of e-learning implementation in Europe. 650 persons responded to this survey, from European Union, European countries other than those of European Union and other unspecified countries in the world, with percentage of 84,6 and 5.5 respectively. The survey was specially focused on universities and training institutions, whether public or private. It reflected that, demand on e-learning was in progressive increase through Europe, and its methods were in common use in training. Regarding economical aspect, it was found that companies of less than 50 employees, tended to use e-learning in training more than big companies (European Center for Development of Vocational Training) [21]. Within the last few years, market of e-learning has increased by many folds [22], [23],[2] from 6.6 billion dollars in 2002, 24 billion dollars in 2006, 52 billion dollars in 2010, and it is expected to reach 107 billion dollars by 2015 . This means that there is increase of $25 \%$ annually in this market. The growth covers software industry, curricula, construction of lecture presentation studios, communication equipment and search engines. Further, there is also increase of indirect economical benefits such as employing graduates, engineers and designers of lectures and communication technologies, in addition to huge manpower which is expected to enter this vast educational process. A lot of parents are paying direct or indirect high expenses of private lessons. Will e-learning be good and cost effective tool of education and of better results than private lessons? Anyway, e-learning market is a growing and open market of good economical feasibility.

\section{CONCLUSION AND RECOMMEND- ATIONS}

In conclusion it can be stated that, e-learning is a reality of modern life. Its advantages not only limited to educational and economical aspects, but can be extended to achieve more humane and social values, most important of which acquaintance between people and accessibility of education for those who are poor or could not complete their education at early age for any reason. All developed nations are now ready for e-learning, either for purposes of broadening education chances or for more educational accomplishments. Arab and African countries, with the Kingdom of Saudi Arabia at top, come relatively in the third position according to country's categorization. Sudan has a good infrastructure and acceptable scientific capability, but it must do more efforts regarding technical requirements, in order to maximize the benefits of e-learning.

\section{REFERENCES}

[1] Oblinger D G and Katz R N (2000). Navigating the Sea Of ' $E$ ' The ' $E$ ' Is For Everything. In: R N Katz and D G Oblinger (Eds.) San Francisco, Jossey-Bass Inc.

[2] Arleta C (2003) Hong Kong-based director of IBM Learning Solutions in the Asia Pacific region, The Economist Intelligence Unit Limited and IBM Corporation.

[3] Pisapia , John R.; Knutson, Kim; Coukos, Eleni D. (1999-11-00). The Impact of Computers on Student Performance and Teacher Behaviour. [Paper Presented at the Annual Meeting of the Florida Educational Research Association $\left(44^{\text {th }}\right.$, Deerfield Beach, FL, November 1012,1999)]. Reports - Evaluative (142)-Speeches Meeting Parers (150).

[4] Andone, Diana, Dron , Jon , Pemberton, Lyn, Boyne, Chris . (2007). E-Learning Environments for Digitally Minded Students (EJ747662).[Journal of Interactive learning ] [Research, V $|8 \mathrm{~N}| \mathrm{p} 41-53$ ].

[5] Daniel J S (2002) Technology and Education: Adventures in the Eternal Triangle. Keynote Address to the 10th European Congress and Trade Fair For Educational and Information Technology Proceedings. U Back and W Sommer (Eds.) Karlsruhe: Karlsruher Messe-und Kongress-GmbH.

[6] Dixon, J. K., \& Ruetten, M. M. (1999, October). A slice of data. Learning \& Leading with Technology, 27(2), 2227.

[7] Rodgers, B. (2001, January). Re: Educator Competencies. Available: email received.

[8] Guhlin, Miguel; Ornelas, Leo; Diem, Richard .(2002-0400). Methods That Work : Educa Competencies For 
Technology in Public Schools. [Paper Presented at the Annual. Meeting of the American Educational Research Association (New Orleans, LA)].

[9] Karim,M.R.A. \& Hashim ,Y.,(2004)" The Experience of the E-Learning Implementation at the University Pendidikan Sultan Idris" Malaysia Online Journal of Instructional Technology (MOJIT), Vol. 1, No. 1, pp 5059, August, ISSN: 1823-1144

[10] Fast Facts About Online Learning, www.inacol.org. (2012)

[11] Boyd,Sally. (1998). Computer in Classrooms : New Zealand Council for Educational Research, Wellington. [ISBN-1-877140-48-1].

[12] Song, Brett Hwi-Gook; Rii, Hae Un; Moon, Mija. (1996).The KidNet Movement of Innovation in Education. URL: http://www.isoc.org/whatis/conferences/inet96/proceedin gs/D2 /D2_2.htm, Montreal, Canada.

[13] Fantookh and Abdel-Qader Abdullah. (1418) e. "Internet for Arab user." First Edition; Obeikan Bookstore.

[14] AKyurekoglu, Hasan. (2000). Perceptions of Teachers at Miami Shores/Barry University (MSBU) Charter School of Using Computers in Their Classrooms for Teaching. [In: Society for Information Technology \& Teacher Education International Conference: Proceedings of SITE $2000\left(11^{\text {th }}\right.$, San Diego, California, February 812,2000). Volumes 1-3; see IR 020112 ].

[15] Sudanese Examination Committee Report(2012) www.MOE.EDU.SD

[16] Informatics development fund, NTC Sudanese (National Authority for Telecommunications)(2012 http://www.ntc.gov.sd/index.php?n=bGFuZz1zZ\%3D\% $3 \mathrm{D}$
[17] Monique Conn, head of programmes at the international Baccalaureate Organization, Geneva, The Economist Intelligence Unit Limited and IBM Corporation 2003.

[18] African virtual university programs, www.avu.org (2012)

[19] Prof. Dr. Coskun BAYRAK / Anadolu University/Eskisehir, TURKEY(2002) Res. Ass. Eren KESIM/Anadolu University/Eskisehir, TURKEY [University's Institute of Educational Sciences] . (An Evaluation with Respect to e-Learning and Economic / Analysis of the Graduate Program Offered in Anadolu)

[20] Greeke, Sigala, M (2001), e-commerce/ Modelling emarketing strategies: Internet presence and exploitation of Greek hotels. Journal of Travel \& Tourism Marketing 2001 Vol. 11 No.2/3 pp. 83-103

[21] Brussels, Belgium. (2001-05-00). Elearning Survey: What Is the Extent of Elearning in Europe? [European Centre for the Development of Vocational Training, Thessaloniki (Greece)]. Special report on the occasion of the European elearning Summit.

[22] www.informationweek.com/news/201311139-Cached InformationWeek connecting the Business Technology Community 2014 (web site).

[23] Global eLearning Market to Reach \$107.3 Billion by 2015, According to New Report by Global Industry Analysts. www.prweb.com/releases/elearning/.../elearning/prweb4 531974.htm-Cached.

[24] Iraklis Varlamis, Ioannis Apostolakis (2006). The Present and Future of Standards for E-Learning Technologies. Interdisciplinary Journal of Knowledge and Learning Objects. (Volume 2). 